\title{
Optimization of Solid Phase Microextraction Procedure Followed by Gas Chromatography with Electron Capture Detector for Pesticides Butachlor and Chlorpyrifos
}

\author{
Fateme Ghavidel ${ }^{1}$, Seyed Jamaleddin Shahtaheri ${ }^{1,2 *}$, Reza Khani Jazani ${ }^{3}$, \\ Marzieh Torabbeigi ${ }^{3}$, Abbas Rahimi Froushani ${ }^{4}$, Monireh Khadem ${ }^{1}$ \\ ${ }^{1}$ Department of Occupational Health Engineering, School of Public Health, Tehran University of Medical \\ Sciences, Tehran, Iran \\ ${ }^{2}$ Institute for Environmental Research, Tehran, Iran \\ ${ }^{3}$ Faculty of Health, Safety, and Environment, Shahid Beheshti University of Medical Sciences, Tehran, Iran \\ ${ }^{4}$ Department of Epidemiology and Biostatistics, School of Public Health, Tehran University of Medical Sciences, \\ Tehran, Iran \\ Email: shahtaheri@sina.tums.ac.ir
}

Received 13 April 2014; revised 26 May 2014; accepted 10 June 2014

Copyright (C) 2014 by authors and Scientific Research Publishing Inc.

This work is licensed under the Creative Commons Attribution International License (CC BY).

http://creativecommons.org/licenses/by/4.0/

(c) (i) Open Access

\section{Abstract}

In this study, headspace solid phase microextraction (HS-SPME) followed by gas chromatography using electron capture detection system (GC-ECD) were developed for the determination of chloraacetanilide (butachlor) and chlorpyrifos presented in biological samples. Different parameters affecting the extraction procedure were optimized including extraction time ( 30 minutes), extraction temperature $\left(80^{\circ} \mathrm{C}\right)$, sample volume $(3 \mathrm{~mL})$, sample $\mathrm{pH}(2)$, added $\mathrm{NaCl}(0.3 \mathrm{gram})$ and sample stirring rate $(400 \mathrm{rpm})$. Different concentrations of $1-100 \mathrm{ng} / \mathrm{ml}$ were applied for butachlor and a linear calibration curve was obtained. Furthermore, a similar linearity was obtained for chlorpyrifos, using a concentration range of $1-250 \mathrm{ng} / \mathrm{ml}$. The limit of detection (LOD) obtained for butachlor and chlorpyrifos were 0.088 and $0.53 \mathrm{ng} / \mathrm{ml}$ respectively. The optimized methods for both compounds were validated using two concentrations of 25 and $50 \mathrm{ng} / \mathrm{ml}$ in spiked urine samples. Obtained recoveries of spiked urine samples were $83.06 \%-99.8 \%$ with RSD of lower than $11 \%$. Optimized technique was simple, inexpensive, solvent free and fast in comparison with other conventional methods and had compatibility with the chromatographic analytical system. This method offers low detection limits to analyze pesticides in urine samples that are very important Corresponding author.

How to cite this paper: Ghavidel, F., et al. (2014) Optimization of Solid Phase Microextraction Procedure Followed by Gas Chromatography with Electron Capture Detector for Pesticides Butachlor and Chlorpyrifos. American Journal of Analytical Chemistry, 5, 535-546. http://dx.doi.org/10.4236/ajac.2014.59061 
in the exposure monitoring in occupational health.

Keywords

HS-SPME, GC-ECD, Biological Samples, Chlorpyrifos, Butachlor

\section{Introduction}

Pesticides are widely used for agricultural purposes around the world. Application of pesticides in agriculture has increased productivity and has led to the increase yields in farming. Pesticides are biologically active and can be harmful to the variety of non-target organisms (including human) when they are applied [1] [2]. Therefore, nowadays, toxic effects of pesticides on humans and the environment are of very important concern [3]. Among the various pesticides available; butachlor and chlorpyrifos are the ones most widely used in developing countries, including Iran by the relevant plant protection organization. Butachlor is structurally belonging to the chloroacetanilide family, and chlorpyrifos is in the organophosphorus pesticide category. It is worth mentioning that, butachlor is a suspected carcinogen [4], so, it needs to be more monitored in the environment, and as a result, monitoring this pesticide in the environment and human is most important for evaluation of the risk hazards associated with such pesticides [5]. Chlorpyrifos as organophosphorus pesticides is very toxic when absorbed by human being because of its property of acetyl-cholinesterase inhibition [6]. To evaluate exposure to these pesticides and the corresponding health risk, measuring the parent pesticide levels in body fluids may be quite useful [7] [8]. There are some traditional techniques to determine the pesticides such as liquid chromatography and gas chromatography with very low detection limits. But the classical gas chromatographic methods are not satisfactory due to the thermal instability of the organophosphorus molecules and a sample preparation or pre-concentration step is needed to determine the analytes at ppb levels. Several analytical methodologies have been developed for sample preparation to facilitate identification of pesticides from biological and environmental samples. Liquid-liquid extraction (LLE) is one of the conventional methods still being used for the extraction of such pesticides from various matrices [9] [10]. Also, solid-phase extraction (SPE) [11]-[17], supercritical fluid extraction (SFE) [18], and matrix solid-phase dispersion (MSPD) [19] is the other more selective approach in this field. Generally, these methods are multistage, expensive, laborious, and consume long time as well as; in these methods, a large amount of organic solvents are applied to extract the analysts of interest [20].

Modern microextraction techniques such as solid-phase microextraction (SPME), that is a rapid, inexpensive, solvent free and quantitative analytical technique was developed by Pawliszyn et al. in the early 1990s [21] [22]. SPME has been employed as a sample preparation method for the analysis of pesticides in various matrices [23]-[25]. In SPME, headspace (HS) approach is preferred for extracting analytes from biological samples, including blood and urine because of complexity of these matrices [26]. The previous studies about chlorpyrifos have used HS-SPME-GC-ECD and mass method (MS) in water samples, fruits, vegetable, and milk [27] [28]. Moreover, Direct Immersion (DI)-SPME-GC-MS technique has been performed for determining the chlorpyrifos in water samples [29]. HS-SPME procedure has been applied for pesticide's purification in biological samples such as chloraacetanilide [30] and organophosphorus pesticides [31].

In comparison with other methods, there are several more variables affecting the determination of butachlor and chlorpyrifos by HS-SPME method that must be studied and optimized to obtain high analyte recovery and low detection limits. Under the optimum extraction conditions, high extraction efficiency was achieved in a relatively short time. Also, there are very few existing methods to determine butachlor and chlorpyrifos in urine samples specially for monitoring the workers exposure to these compounds. The aim of the study was to develop a HS-SPME procedure by optimizing several extraction parameters, and to validate the optimized method by performing urine sample analysis for simultaneous determination of butachlor and chlorpyrifos. Parameters affecting the extraction efficiency were optimized, i.e. extraction temperature, extraction time, salt addition, sample $\mathrm{pH}$, sample volume, and stirring rate. Through this study, optimum conditions were examined in the real samples. The validation of spiked samples was carried out using the optimum conditions. Limit of detection, limit quantification, and linearity range of the method was established for evaluating the pesticides. This method can lead to low detection limits to analyze pesticides in urine samples that are very important in the occupational 
exposure monitoring.

\section{Materials and Methods}

\subsection{Reagent and Materials}

Standards of pesticides were purchased from Sigma-Aldrich (Germany) including butachlor (97.7\%) and chlorpyrifos $(99.9 \%)$. A stock solution of butachlor $\left(1000 \mathrm{mg} \cdot \mathrm{L}^{-1}\right)$ and chlorpyrifos $\left(2500 \mathrm{mg} \cdot \mathrm{L}^{-1}\right)$ was prepared in acetone and methanol, respectively and stored at $4^{\circ} \mathrm{C}$. All solvents (methanol, acetone, and water) were HPLC grade (Merck-Germany). Other reagents with an analytical grade were obtained from Merck (Germany). Working standard solutions of both pesticides were freshly prepared daily by volume dilution in the HPLC grade water.

\subsection{Biological Samples}

After obtaining approval from Tehran University of Medical Sciences (Vice-Chancellor for Research), all participants signed related consent form for the voluntary participation. Then their urine samples were collected for optimization studies. It is worth to mention that a limited number of healthy and non-exposed persons were randomly selected to study. Urine samples were collected in mornings under documented consent, prepared by adding the appropriate volume of the methanol standard solution, and stored at $4^{\circ} \mathrm{C}$ until use. These urine samples were adopted to test the recovery and reproducibility of the optimized method. Since one of the aims of this study was to introduce a proper method for determination of trace level of pesticides in biological samples, so the urine samples were selected to approve the obtained extraction efficiency in this kind of samples. To test the method recovery using the biological samples, defined concentrations of pesticides were spiked in urine (related to non-exposed persons) and optimized extraction procedure was used to get the recoveries.

\subsection{HS-SPME Extraction Procedure}

The SPME device for manual extraction purchased from Supelco (Bellefonte, PA, USA). Polydimethylsiloxane (PDMS $100 \mu \mathrm{m}$ ) fibres were used as extraction phase because of its great sensitivity. Before using, fibers were conditioned in the injection port of the gas chromatograph for $0.5 \mathrm{~h}$ at $250^{\circ} \mathrm{C}$ according to the recommended instructions by the manufacturer. SPME procedure was performed in biological samples by placing $500 \mu \mathrm{l}$ of urine sample and appropriate volumes of pesticide solution at two-level concentrations of 25 and $50 \mathrm{ng} / \mathrm{ml}$ in 5 volumetric flasks. These levels with defined concentrations were selected as spiked samples to optimize variables of interest. Hydrochloric acid and sodium chloride was added for adjusting the $\mathrm{pH}$ at 2 and salt was added to reach the concentration of $10 \%$ and then HPLC grade water was used for adjusting. Three ml volume of this solution was transferred to a $10 \mathrm{ml}$ vial. The vial was rapidly sealed with a silicon septum and aluminum cap. Then; the vial was heated up to $80^{\circ} \mathrm{C}$ in aluminum block heater. Samples were stirred during the extraction time under the magnetic stirring (400 rpm). SPME needle pierced the vial septum in order to expose the fiber (100 $\mu \mathrm{m}$ PDMS) on the headspace of the solution. After 30 minutes, the needle was removed from the vial and inserted into the heated injection port of the GC-ECD for thermal desorption of the sample for 5 minutes.

\subsection{Gas Chromatography}

Chromatographic analysis was carried out by a Varian CP 3800 gas chromatograph equipped with an electron capture detector (ECD). Pesticides were separated in a HP-5 (30 m $\times 0.32 \mathrm{~mm}, 0.25 \mathrm{~m}$ film thickness) column. Nitrogen (99.999\%) with a flow rate of $2 \mathrm{ml} / \mathrm{min}$ was used as a make-up and carrier gas. Samples were analyzed using the following conditions: oven temperature program: initial temperature: $80^{\circ} \mathrm{C}$ hold for $1 \mathrm{~min}$, rate $30^{\circ} \mathrm{C}$ to $200^{\circ} \mathrm{C}$ hold for $2 \mathrm{~min}$, rate $10^{\circ} \mathrm{C}$ to $250^{\circ} \mathrm{C}$ hold for $3 \mathrm{~min}$, rate $20^{\circ} \mathrm{C}$ to $280^{\circ} \mathrm{C}$ hold for $4 \mathrm{~min}$. The injector temperature was $280^{\circ} \mathrm{C}$. The injector was operated in the split less mode. Detector temperature (ECD) was set at $300^{\circ} \mathrm{C}$.

\subsection{Data Analysis}

The statistical calculations and analysis were performed using SPSS version 16. Some tests such as pair T-test and scheffe analysis of variance were used for data analyzing. The level of significance was taken as $\mathrm{p}<0.05$. In 
order to optimize the method, a constant concentration was used for each pesticide. For each level of intended variables, three samples with defined concentration were prepared and the mean of extraction efficiencies calculated after analyzing the analytes. Then according to obtained data, the optimum level was selected for every variable.

\section{Results}

\subsection{Method Optimization}

\subsubsection{Extraction Temperature}

The effect of temperature on extraction efficiency was evaluated from $40^{\circ} \mathrm{C}$ to $80^{\circ} \mathrm{C}$. The highest extraction efficiency for butachlor was obtained at $80^{\circ} \mathrm{C}$. This was due to increased transmission of an analyst into the headspace and hence, into the fiber with increasing temperature. The response of chlorpyrifos increased slightly from $40^{\circ} \mathrm{C}$ up to $60^{\circ} \mathrm{C}$. After that, the higher temperature had no significant effect on extraction rate (Figure 1). It means that the response is nearly constant in temperatures from $60^{\circ} \mathrm{C}$ to $80^{\circ} \mathrm{C}$. Since the best response for butachlor obtained in the temperature $80^{\circ} \mathrm{C}$, for improving the simultaneous extraction of butachlor and chlorpyrifos, temperature of $80^{\circ} \mathrm{C}$ was chosen as the optimum temperature.

\subsubsection{Extraction Time}

The effect of extraction time was evaluated by exposing the fiber to the headspace of the samples at different extraction times, including 5, 10, 30, and 60 minutes. Equilibrium time for butachlor and chlorpyrifos (from 5 minutes to 30 minutes) was remarkable and showed an increased extraction rate. However, larger extraction time for both pesticides was unsuitable, because the responses of both pesticides were decreased when the extraction time exceeded 30 minutes (Figure 2). Therefore, extraction time of 30 minutes was selected at an optimum extraction time, and rms do not have to be defined. Do not use abbreviations in the title or heads unless they are unavoidable.

\subsubsection{Salt Addition}

The influence of salt on extraction efficiency was investigated for both pesticides by adding various amounts of $\mathrm{NaCl}$ in sample solution, including $0 \%, 1 \%, 5 \%$, and $10 \%(\mathrm{w} / \mathrm{v})$ of sodium chloride. As it can be seen in Figure 3 , in general, super saturation of the sample with salts is most effective for the extraction of analytes onto the fiber because of the salting-out effect [32]. The response of chlorpyrifos was increased from $0 \%$ to $10 \%$ of $\mathrm{NaCl}$, and the highest extraction efficiency was obtained in $10 \%$ of $\mathrm{NaCl}$. The effect of $\mathrm{NaCl}$ on extraction efficiency of butachlor showed that, the amount of $\mathrm{NaCl}$ from $0 \%$ to $5 \%$ increased the efficiency. However, the higher amount of sodium chloride for butachlor showed a slight decrease. Therefore, $\mathrm{NaCl} 10 \%$ was chosen as an

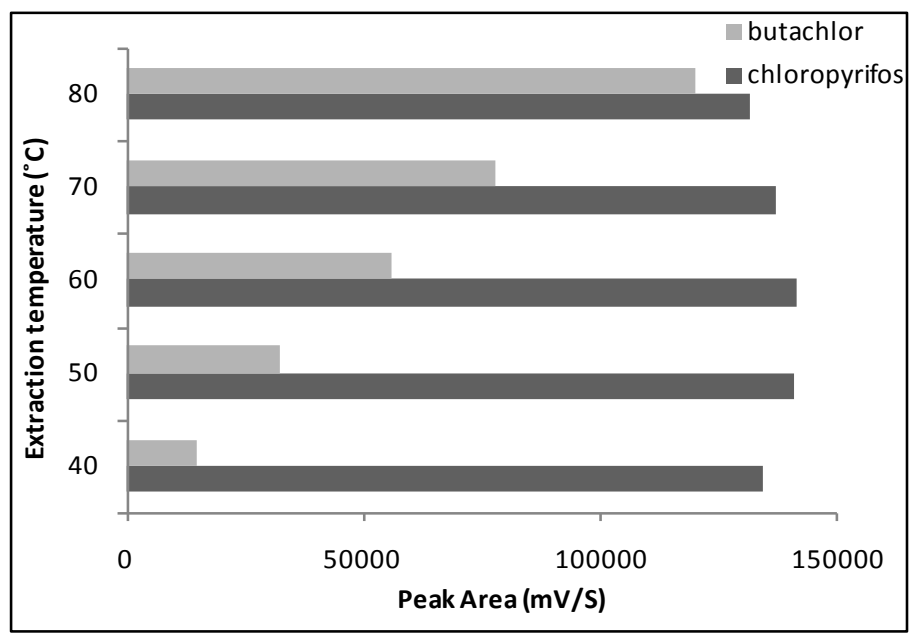

Figure 1. Influence of extraction temperature on the extraction efficiency (Extraction time: $30 \mathrm{~min}$, sample volume: $3 \mathrm{ml}$, sample $\mathrm{pH}$ : 2, $\mathrm{NaCl}: 10 \%$ (0.3 gram), stirring rate: $400 \mathrm{rpm})$. 


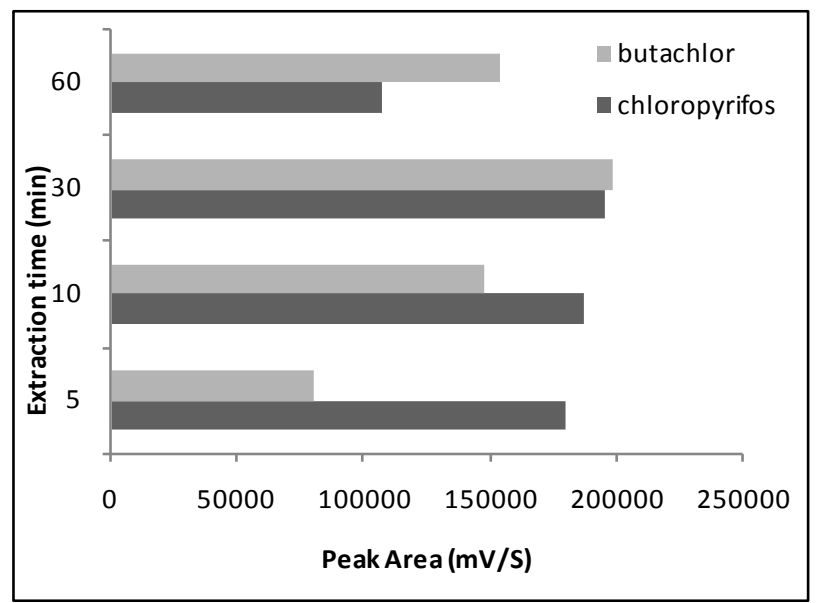

Figure 2. Influence of extraction time on the extraction efficiency (Extraction temperature: $80^{\circ} \mathrm{C}$, sample volume: $3 \mathrm{ml}$, sample $\mathrm{pH}: 2, \mathrm{NaCl}: 10 \%$ (0.3 gram), stirring rate: $400 \mathrm{rpm})$.

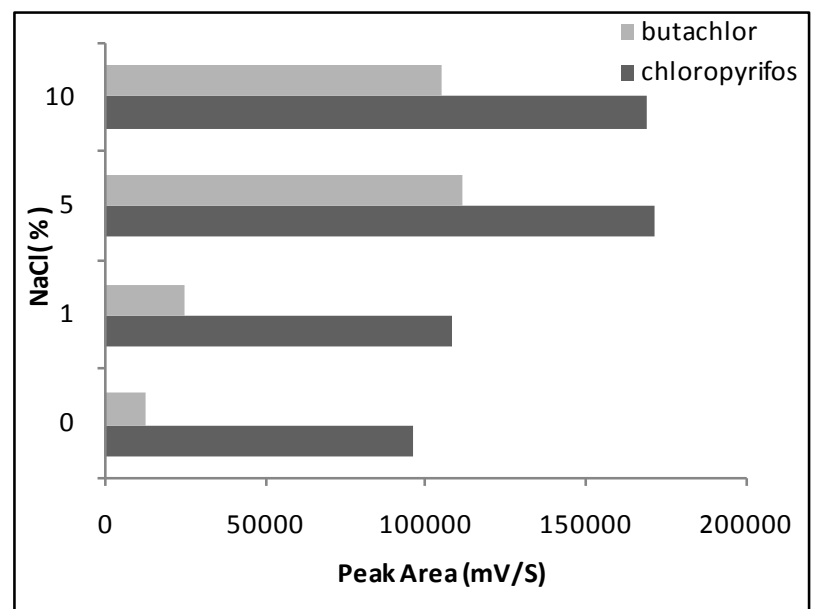

Figure 3. Influence of salt addition on the extraction efficiency (Extraction time: $30 \mathrm{~min}$, extraction temperature: $80^{\circ} \mathrm{C}$, sample volume: $3 \mathrm{ml}$, sample $\mathrm{pH}: 2$, stirring rate: $400 \mathrm{rpm}$ ).

optimum amount of salt added to the butachlor and chlorpyrifos samples. Although according to figure, the optimal salt concentration seems to be $5 \%$ for both butachlor and chlorpyrifos, there was no significant difference between $5 \%$ and $10 \%$ of $\mathrm{NaCl}$ for both of them. And since the higher ionic strength had no negative impact on the extraction efficiency and even may improve it in presence of other pesticides, $10 \%$ of $\mathrm{NaCl}$ was selected as proper salt concentration.

\subsubsection{Effect of $\mathrm{pH}$}

The effects of $\mathrm{pH}$ on extraction efficiency for butachlor and chlorpyrifos have been shown in Figure 4. The extraction efficiency of these pesticides was studied at various pHs from 2 to 5 . The efficiency of both pesticides was decreased significantly when $\mathrm{pH}$ increasing. Hence, a sample $\mathrm{pH}$ of 2 was chosen as the optimum $\mathrm{pH}$ for each two pesticides.

\subsubsection{Sample Stirring}

The effect of sample stirring was evaluated at different stirring rates (200, 400, and $700 \mathrm{rpm})$. Stirring rates from 200 to $400 \mathrm{rpm}$ showed that the peak areas of both pesticides were increased with stirring rate. The extraction efficiencies of Butachlor and chlorpyrifos decreased significantly at higher stirring rates (from 400 to $700 \mathrm{rpm}$ ) 
(Figure 5). Therefore, the velocity of $400 \mathrm{rpm}$ was chosen for subsequent analyses.

\subsubsection{Sample Volume}

To evaluate the effect of the sample volume on the efficiency of HS-SPME, the sample volumes of 2 to $4 \mathrm{ml}$ were selected. For both pesticides, the maximum response was obtained when $3 \mathrm{ml}$ sample was used. At the higher sample volumes, as it can be seen in Figure 6, extraction efficiency showed a considerable decrease. However, subsequent analyses were performed at $3 \mathrm{ml}$ sample volume.

\subsection{Method Validation}

The method was validated using obtained optimized conditions. The detection limits (LODs), quantification limits (LOQs), the inter- and intra-day precisions (RSD), the linearity, and the recoveries were calculated. The results were tabulated in Table 1 and Table 2.

Linear standard curves in the range of $1-100 \mathrm{ng} / \mathrm{ml}$ and $1-250 \mathrm{ng} / \mathrm{ml}$ for butachlor and chlorpyrifos were obtained each day for 6 consecutive days, respectively. The obtained correlation coefficients $\left(\mathrm{r}^{2}\right)$ were 0.9928 or greater (Table 1). Intra- and inter-day precisions of the method were determined by two spiked extracted samples

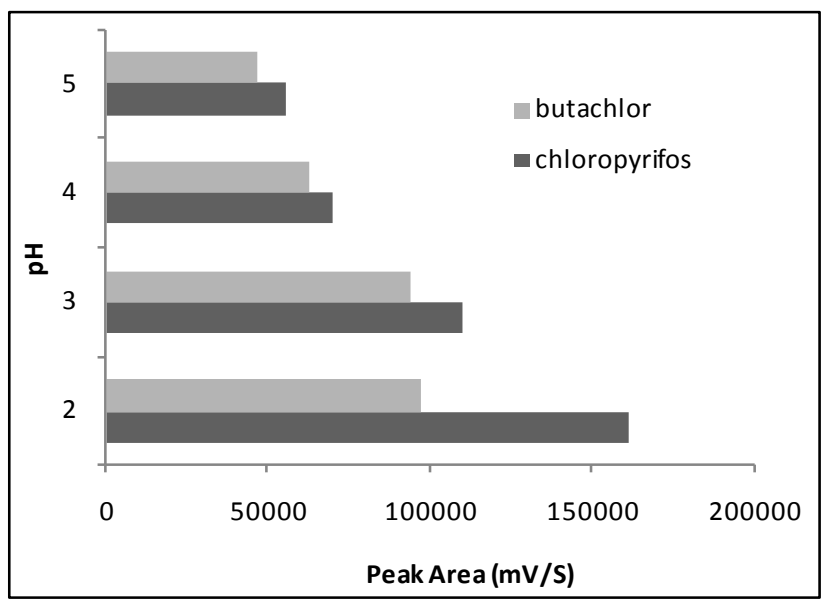

Figure 4. Influence of sample $\mathrm{pH}$ on the extraction efficiency chloroprifos and butachlor (Extraction time: $30 \mathrm{~min}$, extraction temperature: $80^{\circ} \mathrm{C}$, sample volume: $3 \mathrm{ml}, \mathrm{NaCl}: 10 \%$ (0.3 gram), stirring rate: $400 \mathrm{rpm})$.

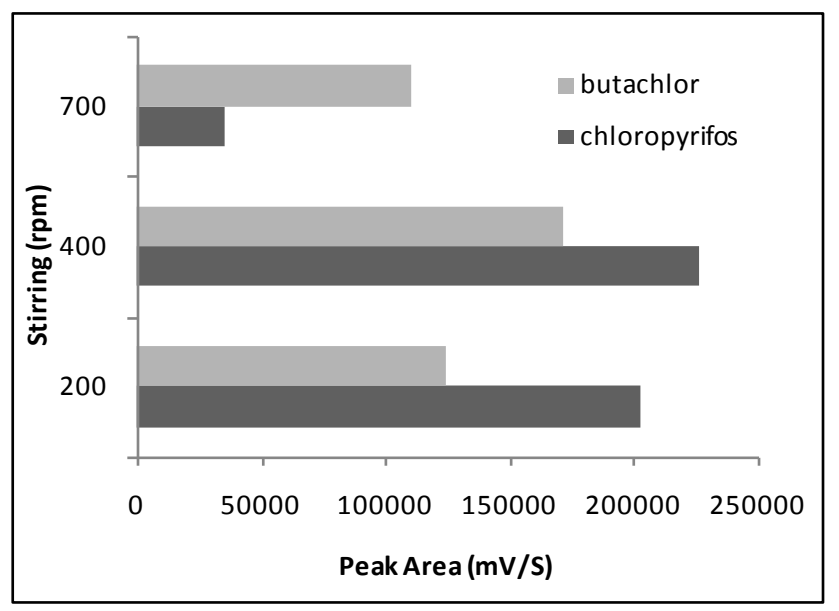

Figure 5. Influence of stirring speed on the extraction efficiency (Extraction time: $30 \mathrm{~min}$, extraction temperature: $80^{\circ} \mathrm{C}$, sample volume: $3 \mathrm{ml}$, sample $\mathrm{pH}: 2$, $\mathrm{NaCl}: 10 \%$ (0.3 gram)). 


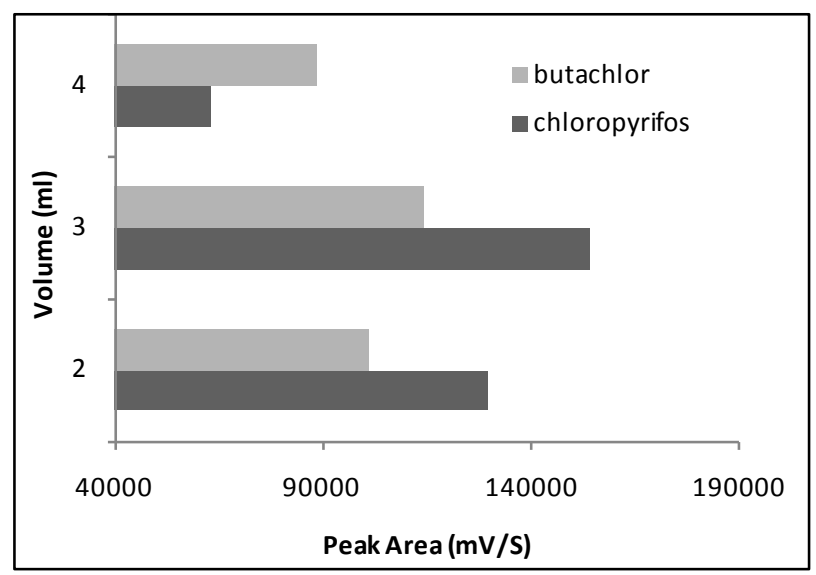

Figure 6. Influence of sample volume on the extraction efficiency (Extraction time: $30 \mathrm{~min}$, extraction temperature: $80^{\circ} \mathrm{C}$, sample $\mathrm{pH}$ : 2 , stirring rate: $400 \mathrm{rpm}, \mathrm{NaCl}: 10 \%$ (0.3 gram)).

Table 1. Analytical performance of the optimized SPME method for two pesticides.

\begin{tabular}{ccccc}
\hline Analyte & Linear rang $(\mathbf{n g} / \mathbf{m l})$ & Correlation coefficient $\left(\mathbf{R}^{2}\right)(\mathbf{n g} / \mathbf{m l})$ & LODs $(\mathbf{n g} / \mathbf{m l})$ & LOQs $(\mathbf{n g} / \mathbf{m l})$ \\
\hline Butachlor & $1-100$ & 0.992 & 0.0888 & 0.269 \\
Chlorpyrifos & $1-250$ & 0.997 & 0.053 & 0.161 \\
\hline
\end{tabular}

Table 2. Inter-day and intra-day reproducibility of method for spiked urine sample.

\begin{tabular}{cccccc}
\hline \multirow{2}{*}{ Analytes } & \multirow{2}{*}{ Concentration } & \multicolumn{2}{c}{ Inter-day (n= 6) } & \multicolumn{2}{c}{ Intra-day (n = 6) } \\
\cline { 3 - 6 } & & Recovery (\%) & RSD (\%) & Recovery (\%) & RSD (\%) \\
\hline \multirow{2}{*}{ Butachlor } & 25 & 90.65 & 8.098 & 87.70 & 8.266 \\
& 50 & 96.70 & 6.594 & 97.47 & 4.601 \\
Chlorpyrifos & 25 & 83.06 & 10.06 & 85.59 & 10.206 \\
& 50 & 99.60 & 4.833 & 99.81 & 5.523 \\
\hline
\end{tabular}

at concentrations of 25 and $50 \mathrm{ng} / \mathrm{ml}$ followed by analysis each day for 6 consecutive days to estimate inter-day (day-to-day) reproducibility as well as six times a day to estimate intra-day (within the day) reproducibility. Totally, 72 analyses were performed to determine intra and inter reproducibility. In within day experiments evaluation, one urine samples per day were analyzed six times for three consecutive days (36 analyses at two intended concentrations). In day-to-day reproducibility, experiments were performed every day for 6 consecutive days with three replications (36 analyses at two intended concentrations). Figure 7 shows the chromatograms of urine sample with and without spiked pesticides. The optimized extraction protocol was followed along with optimum chromatographic conditions. The measurement of butachlor and chlorpyrifos on each day of the analysis was calculated by comparing it with the extracted calibration curve generated on that day. Intra-day variation or reproducibility of the method was assessed by calculating the relative standard deviation (RSD) (Table 2). As indicated by RSD, the precision of the optimized method was high enough (RSD less than 11\%). The relative standard deviation of $50 \mathrm{ng} / \mathrm{ml}$ showed lower RSD (higher precision). Experiments were also undertaken to assess Inter-day reproducibility. The results are shown in Table 2. The obtained RSD indicates that the method was much more precise at two concentrations. The recoveries obtained by SPME-GC-ECD method was between 83\% - 99\% that shown in Table 2.

\section{Discussion}

In this study, headspace solid phase microextraction (HS-SPME) method in combination with Gas Chroma- 


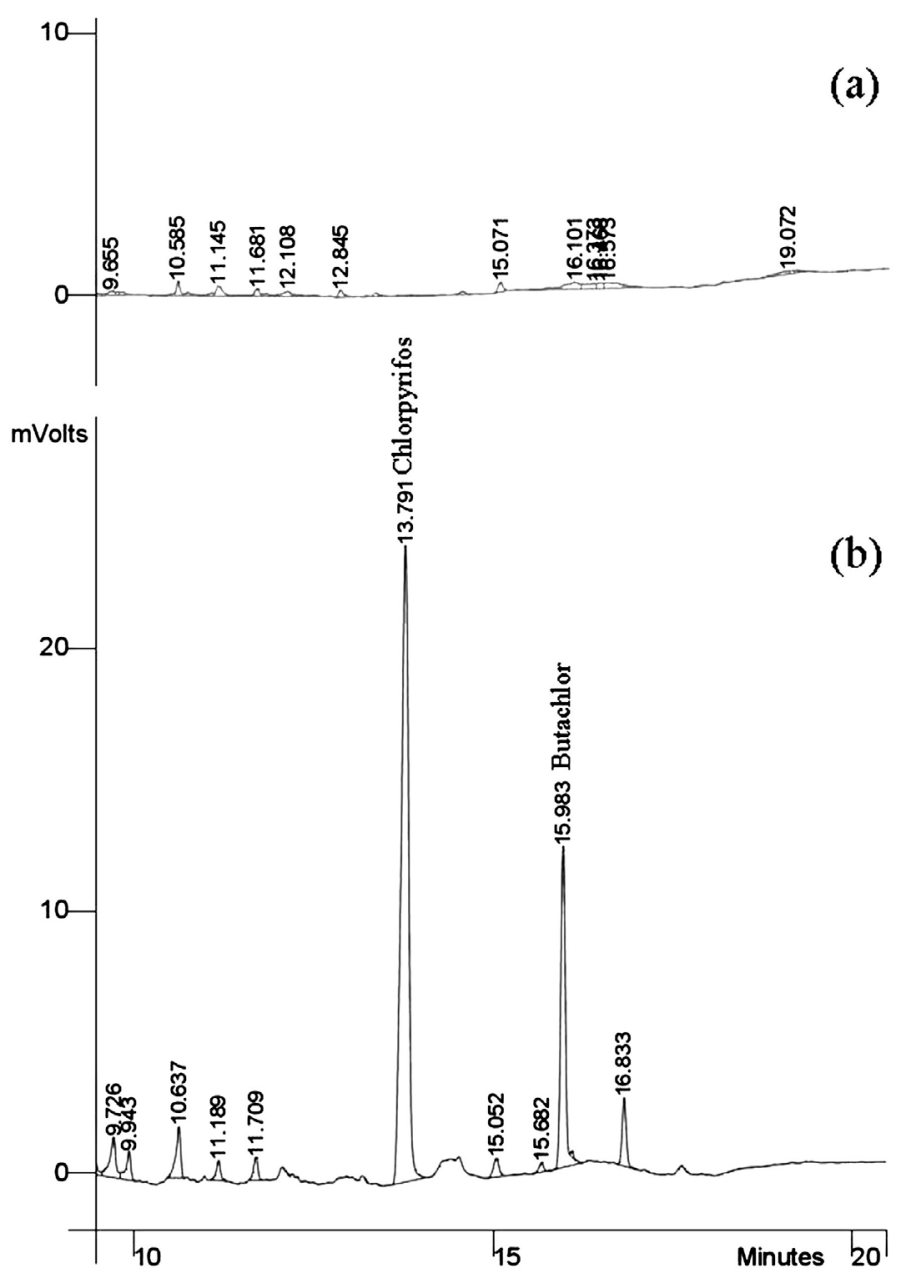

Figure 7. Chromatograms of urine sample (a) without and (b) with spiked sample of chloroprifos and butachlor.

Tography-Electron Capture Detector (GC-ECD) was used for the extraction and quantification of butachlor and chlorpyrifos. This technique is simple, inexpensive, and fast compared to other conventional methods [21] [22] [33] [34]. Through this study, different parameters affecting the extraction procedure were optimized. Temperature is the main parameter that can affect the extraction of the analyte in HS-SPME. By raising temperature, the partition constant of the analyte was increased in favour of the gaseous sample; therefore, partitioning of the analytes between the sample and headspace can reach equilibrium more quickly. Thus, the analyte can exist in the headspace of the sample and can be extracted by the SPME fiber. Increasing temperature causes an increase in the amount of the analyte extracted. The obtained results indicated that, temperature up to $60^{\circ} \mathrm{C}$ could increase the amount of the analyte extracted for chlorpyrifos, where it reached a plateau and remained constant. No significant effect was seen at higher temperatures $(p>0.05)$ and highest extraction efficiency for butachlor was obtained at $80^{\circ} \mathrm{C}$. These results are consistent with previously reported data [30] [35].

The effect of extraction time of 5 - 60 minutes on extraction efficiency indicated that, up to 30 minutes there was a significant effect in all experiments for both pesticides. It means that based on the peak obtained from the GC, the higher amounts of analytes could efficiently extract from the samples with increasing the time up to 30 minutes. After this time, analytes were desorbed from the fiber to the headspace and the amounts adsorbed on the fiber were slightly decreased. The more extraction time can decrease the distribution coefficient of the analyte [36].

$\mathrm{NaCl}$ is also a parameter that can affect extraction efficiency, because the partition constant of the analyte can be changed in its presence, and therefore, more analyte may be exist in the headspace of the sample. In fact, the 
solubility of the analyte decreases when $\mathrm{NaCl}$ is added.

Because of the salting-out effect, super saturation of the sample with salts can cause the extraction of analytes onto the fiber [32]. Also, previous studies have shown that ionic strength can improve extraction efficiency [37]. Therefore, the effect of extra $\mathrm{NaCl}$ on the extraction efficiency of both pesticides was shown. There is a competition among compounds with different polarity for the fiber in SPME. Also intensities of competition in presence of various pesticides are different. So, there are some differences in various studies due to different existing pesticides. For butachlor, the amount of $\mathrm{NaCl}$ from $0 \%$ to $5 \%$ increased the extraction rate; after that, there was no significant difference $(\mathrm{p}>0.05)$ between $5 \%$ and $10 \%$ of $\mathrm{NaCl}$ and the extraction remained constant.

The $\mathrm{pH}$ of the sample was the main parameter which could theoretically affect extraction efficiency. The ionic strength of the analytes could be changed by increasing or decreasing $\mathrm{pH}$. The extraction efficiency of both pesticides was decreased significantly when $\mathrm{pH}$ was increased. In general, the sample is acidified for the extraction of acidic analytes and is made alkaline for the extraction of basic analytes, because, compounds for extraction should be in the molecular form [38].

Sample agitation is another important parameter that has to be optimized. It can increase extraction efficiency. The stirring process accelerates the transfer of an analyst into the headspace and hence, into the fiber coating. Although the equilibration time decreases with the increasing stirring rate, quick agitation depends on being rotational speed might cause a change in the equilibration time [38]. Higher stirring rate may cause a negative effect on the reproducibility of the sorption condition because of spattering.

For optimizing the volume of the sample, since the size of headspace vials was $10 \mathrm{ml}, 2$ - $4 \mathrm{ml}$ of the sample volume was tested. By increasing the volume of the sample up to $3 \mathrm{ml}$, the amount of the analyte extracted can be increased. Gorecki and Pawliszyn in their recent paper have reported that, a large sample volume can provide the best results [39]. At the higher sample volumes, extraction rate showed a considerable decrease due to lower headspace. For rapid extraction, a large capacity of the headspace is required. It is achievable when there is a large headspace-to sample volume ratio. On the other hand, increasing the sample volume in a constant vial size leads to the lower head space capacity. In present study, one vial size was selected because of the poorer precision using variable vial volumes. Therefore, increasing the sample volume decreased the capacity of headspace, resulting lower extraction efficiency. Also the effect of sample volume on the magnitude of extraction depends on the analyte (how much is the analyte soluble and volatile). Gorecki and Pawliszyn have worked on the partition coefficient $(\mathrm{K})$ values on their study and express that the large sample volumes is used to determine $\mathrm{K}$ values, as they enable broader ranges of values with good accuracy. On the other hand, they have emphasized that a large headspace capacity may lead to the loss of sensitivity. These reasons may explain the difference between the results of studies.

Finally, validation of the method was performed using spiked samples and standards to determine the pesticides in urine samples. The recoveries and RSD values in the present study were compared with those values in the existing methods [27] [32] [40] and the significant differences were found between them. These mentioned studies expressed the different RSDs and Extraction recoveries (like RSD $<19 \%$ ), but there were significant differences between them and present study. The obtained recoveries in this study, ranging from $88 \%$ to $97 \%$, were higher than the mentioned investigations. The optimized method is sensitive enough for all concentrations (RSD less than 11\%). Based on results, the proposed method is easy, fast, precise, and reproducible with wide linear range and it does not require any toxic solvent for extraction. In addition, it can be seen a successful application of the HS-SPME technique to analyze the pesticides at a low concentration level in urine samples.

\section{Conclusion}

The SPME procedure seems to be a useful method for qualitative and quantitative evaluation of butachlor and chlorpyrifos in biological samples. This technique is simple, inexpensive, fast compared to the more conventional methods. To implement HS-SPME-GC-ECD, it was necessary to optimize the parameters affecting the extraction of the analytes. The optimum extraction conditions were achieved. Finally, validation of methods for determining butachlor and chlorpyrifos in the spiked urine sample was performed. Inter-day and intra-day relative standard deviation of method was evaluated by spiked urine sample with butachlor and chlorpyrifos. The results indicated that, the developed SPME-GC-ECD method was suitable for biological monitoring of butachlor and chlorpyrifos. 


\section{Acknowledgements}

This research has been supported by Tehran University of Medical Sciences grant (Project No. 15212). Authors acknowledge the University for all valuable supports.

\section{References}

[1] Hsu, J.P., Herbert, G., Wheeler, D.E., Camann, H.J., et al. (1988) Analytical Methods for Detection of Nonoccupational Exposure to Pesticides. Journal of Chromatographic Science, 26, 181-189. http://dx.doi.org/10.1093/chromsci/26.4.181

[2] Matsumura, F. (1985) Toxicology of Insecticides. 2nd Edition, Plenum, New York. http://dx.doi.org/10.1007/978-1-4613-2491-1

[3] Ritter, L., Goushleff, N.C.I., Arbuckle, T., Cole, D., Donald, M. and Raizenne, M. (2006) Addressing the Linkage between Exposure to Pesticides and Human Health Effects-Research Trends and Priorities for Research. Journal of Toxicology and Environmental Health, 9, 441-456. http://dx.doi.org/10.1080/10937400600755895

[4] Farombi, O.E., Ajimoko, Y.R. and Adelowo, O.A. (2008) Effect of Butachlor on Antioxidant Enzyme Status and Lipid Peroxidation in Fresh Water African Catfish, (Clarias gariepinus). International Journal of Environmental Research and Public Health, 5, 423-427. http://dx.doi.org/10.3390/ijerph5050423

[5] Aktar, W., Sengupta, D. and Chowdhury, A. (2009) Impact of Pesticides Use in Agriculture: Their Benefits and Hazards. Interdisciplinary Toxicology, 2, 1-12. http://dx.doi.org/10.2478/v10102-009-0001-7

[6] Costa, L.G. (2006) Current Issues in Organophosphate Toxicology. Clinica Chimica Acta, 366, 1-13. http://dx.doi.org/10.1016/j.cca.2005.10.008

[7] Otero, R., Santiago Silva, M. and Grimalt, J.O. (1997) Hexachlorocyclohexanes in Human Blood Serum. Journal of Chromatography A, 778, 87-94. http://dx.doi.org/10.1016/S0021-9673(97)00339-7

[8] Burse, V.W., Head, S.L., Korver, M.P., McClure, P.C., Donahue, J.F. and Needham, L.L. (1990) Determination of Selected Organochlorine Pesticides and Polychlorinated Biphenyls in Human Serum. Journal of Analytical Toxicology, 14, 137-142. http://dx.doi.org/10.1093/jat/14.3.137

[9] Pico, Y., Font, G., Molto, J.C. and Manes, J. (2000) Pesticide Residue Determination in Fruit and Vegetables by Liquid Chromatography-Mass Spectrometry. Journal of Chromatography A, 882, 153-173. http://dx.doi.org/10.1016/S0021-9673(00)00294-6

[10] Jimenez, J.J., Bernal, J.L., del Nozal, M.J., Novo, M., Higes, M. and Llorente, J. (2000) Determination of Rotenone Residues in Raw Honey by Solid-Phase Extraction and High-Performance Liquid Chromatography. Journal of Chromatography A, 871, 67-73. http://dx.doi.org/10.1016/S0021-9673(99)01063-8

[11] Tsydenova, O.V., Sudaryanto, A., Kajiwara, N., Kunisue, T., Batoev, V.B. and Tanabe, S. (2007) Organohalogen Compounds in Human Breast Milk from Republic of Buryatia, Russia. Environmental Pollution, 146, 225-235. http://dx.doi.org/10.1016/j.envpol.2006.04.036

[12] Shahtaheri, S.J., Abdollahi, M., Golbabaei, F., Rahimi-Froushani, A. and Ghamari, F. (2004) Optimization of SPE for Analysis of Mandelic Acid as a Biomarker of Exposure to Ethyl Benzene. Iranian Journal of Environmental Health Science \& Engineering, 1, 70-80.

[13] Shahtaheri, S.J., Khadem, M., Golbabaei, F. and Rahimi-Froushan, A. (2006) Pre-Concentration of Cadmium Using Amberlite XAD-4 Prior to Atomic Absorption Spectroscopy. Iranian Journal of Environmental Health Science \& Engineering, 3, 45-52.

[14] Shahtaheri, S.J., Khadem, M., Golbabaei, F. and Rahimi-Froushani, A. (2007) Optimization of Sample Preparation Procedure for Evaluation of Occupational and Environmental Exposure to Nickel. Iranian Journal of Public Health, 36, 73-81.

[15] Shahtaheri, S.J., Ghamari, F., Golbabaei, F., Rahimi-Froushani, A. and Abdollahi, M. (2005) Sample Preparation Followed by High Performance Liquid Chromatographic (HPLC) Analysis for Monitoring of Muconic Acid as a Biomarker of Occupational Exposure to Benzene. International Journal of Occupational Safety and Ergonomics, 11, 337388.

[16] Shahtaheri, S.J., Ibrahimi, L., Golbabaei, F. and Hosseini, M. (2007) Solid Phase Extraction for 1-Hydroxypyrene as a Biomarker of Exposure to PAHs Prior to High Performance Liquid Chromatography. Iranian Journal of Chemistry and Chemical Engineering, 26, 75-81.

[17] Shahtaheri, S.J., Abdollahi, M., Golbabaei, F. and Rahimi-Froushani, A. (2008) Monitoring of Mandelic Acid as a Biomarker of Environmental and Occupational Exposures to Styrene. International Journal of Environmental Research, 2, 169-176.

[18] Barnabas, I.J. and Dean, J.R. (1994) Owen Supercritical Fluid Extraction of Analytes from Environmental Samples, A 
Review. Analyst, 119, 2381-2394. http://dx.doi.org/10.1039/an9941902381

[19] Viana, E., Molto, J.C. and Font, G. (1996) Optimization of a Matrix Solid-Phase Dispersion Method for the Analysis of Pesticide Residues in Vegetables. Journal of Chromatography A, 754, 437-444. http://dx.doi.org/10.1016/S0021-9673(96)00538-9

[20] Barrionuevo, W.R. and Lancas, F.M. (2002) Comparison of Liquid-Liquid Extraction (LLE), Solid-Phase Extraction (SPE), and Solid-Phase Microextraction (SPME) for Pyrethroid Pesticides Analysis from Enriched River Water. Bulletin of Environmental Contamination and Toxicology, 69, 123-128. http://dx.doi.org/10.1007/s00128-002-0018-5

[21] Zhang, Z. and Pawliszyn, J. (1993) Headspace Solid Phase Microextraction. Analytical Chemistry, 65, 1843-1852. http://dx.doi.org/10.1021/ac00062a008

[22] Pan, L. and Pawliszyn, J. (1997) Derivatization/Solid-Phase Microextraction: New Approach to Polar Analytes. Analytical Chemistry, 69, 196-205. http://dx.doi.org/10.1021/ac9606362

[23] Tsoukali, H., Raikos, N., Theodoridis, G. and Psaroulis, D. (2004) Headspace Solid Phase Microextraction for the Gas Chromatographic Analysis of Methyl-Parathion in Post-Mortem Human Samples. Forensic Science International, 143, 127-132. http://dx.doi.org/10.1016/j.forsciint.2004.02.032

[24] Heidari, H.R., Shahtaheri, S.J., Golbabaei, F., Alimohamadi, M. and Rahimi-Froushani, A. (2008) Optimization of Headspace Solid Phase Microextraction Procedure for Trace Analysis of Toluene. International Journal of Occupational Safety and Ergonomics (JOSE), 14, 395-405.

[25] Heidari, H.R., Shahtaheri, S.J., Golbabaei, F., Alimohamadi, M. and Rahimi-Froushani, A. (2009) Trace Analysis of Xylene in Occupational Exposures Monitoring. Iranian Journal of Public Health, 38, 89-99.

[26] Hernandez, F., Pitarch, E., Beltran, J. and Lopez, F.J. (2002) Headspace Solid-Phase Microextraction in Combination with Gas Chromatography and Tandem Mass Spectrometry for the Determination of Organochlorine and Organophosphorus Pesticides in Whole Human Blood. Journal of Chromatography B, 769, 65-77. http://dx.doi.org/10.1016/S1570-0232(01)00627-4

[27] Kin, C.M. and Huat, T. (2010) Headspace Solid-Phase Microextraction for the Evaluation of Pesticide Residue Contents in Cucumber and Strawberry after Washing Treatment. Food Chemistry, 123, 760-764. http://dx.doi.org/10.1016/j.foodchem.2010.05.038

[28] Alvarez, M.F., Llompart, M., Lamasa, J.P., Lores, M., Garcia-Jares, C., Cela, R. and Dagnac, T. (2008) Development of a Solid-Phase Microextraction Gas Chromatography with Microelectron-Capture Detection Method for a Multiresidue Analysis of Pesticides in Bovine Milk. Analytica Chimica Acta, 617, 37-50.

http://dx.doi.org/10.1016/j.aca.2008.01.021

[29] Beceiro-Gonzalez, E., Concha-Grana, E., Guimaraes, A., Goncalves, C., Muniategui-Lorenzo, S. and Alpendurada, M.F. (2007) Optimisation and Validation of a Solid-Phase Microextraction Method for Simultaneous Determination of Different Types of Pesticides in Water by Gas Chromatography-Mass Spectrometry. Journal of Chromatography A, 1141, 165-173. http://dx.doi.org/10.1016/j.chroma.2006.12.042

[30] Namera, A., Watanabe, T., Yashiki, M., Iwasaki, Y. and Kojima, T. (1999) Simple Analysis of Arylamide Herbicides in Serum Using Headspace-Solid Phase Microextraction and GC/MS. Forensic Science International, 103, 217-226. http://dx.doi.org/10.1016/S0379-0738(99)00088-2

[31] Tsoukali, H., Theodoridis, G., Raikos, N. and Grigoratou, I. (2005) Solid Phase Microextraction Gas Chromatographic Analysis of Organophosphorus Pesticides in Biological Samples. Journal of Chromatography B, 822, 194-200. http://dx.doi.org/10.1016/j.jchromb.2005.05.035

[32] Yao, Z.W., Jiang, G.B., Liu, J.M. and Cheng, W. (2001) Application of Solid-Phase Microextraction for the Determination of Organophosphorous Pesticides in Aqueous Samples by Gas Chromatography with Flame Photometric Detector. Talanta, 55, 807-814. http://dx.doi.org/10.1016/S0039-9140(01)00504-5

[33] Bicchi, C., Cordero, C., Liberto, E., Sgorbini, B. and Rubiolo, P. (2007) Reliability of Fibres in Solid Phase Microextraction for Routine Analysis of the Headspace of Aromatic and Medicinal Plants. Journal of Chromatography A, 1152, 138-149. http://dx.doi.org/10.1016/j.chroma.2007.02.011

[34] Sousa, E.T., Rodrigues, F.M., Martins, C.C., de Oliveira, F.S., Pereira, P.A.P. and de Andrade, J.B. (2006) Multivariate Optimization and HS-SPME/GC-MS Analysis of VOCs in Red, Yellow and Purple Varieties of Capsicum chinese sp. Peppers. Microchemical Journal, 82, 142-149. http://dx.doi.org/10.1016/j.microc.2006.01.017

[35] Sakamoto, M. and Tsutsumi, T. (2004) Applicability of Headspace Solid-Phase Microextraction to the Determination of Multi-Class Pesticides in Waters. Journal of Chromatography A, 1028, 63-74. http://dx.doi.org/10.1016/j.chroma.2003.11.066

[36] Doong, R.A., Chang, S.M. and Sun, Y.C. (2000) Solid-Phase Microextraction for Determining the Distribution of Sixteen US Environmental Protection Agency Polycyclic Aromatic Hydrocarbons in Water Samples. Journal of Chromatography A, 879, 177-188. http://dx.doi.org/10.1016/S0021-9673(00)00347-2 
[37] Fernandez Alvarez, M., Liompart, M., Pablo Lamas, J., Lores, M., Garcia-Jares, C., Cela, R. and Dagnac, T. (2008) Development of a Solid Phase Microextraction Gas Chromatography with Microelectron-Capture Detection Method for a Multiresidue Analysis of Pesticides in Bovine Milk. Analytica Chimica Acta, 617, 37-50. http://dx.doi.org/10.1016/j.aca.2008.01.021

[38] Kataoka, H., Lord, H.L. and Pawliszyn, J. (2000) Applications of Solid Phase Microextraction in Food Analysis. Journal of Chromatography A, 880, 35-62. http://dx.doi.org/10.1016/S0021-9673(00)00309-5

[39] Gorecki, T. and Pawliszyn, J. (1997) Effect of Sample Volume on Quantitative Analysis by Solid-Phase Microextraction. Analyst, 122, 1079-1086. http://dx.doi.org/10.1039/a701303e

[40] Xua, X.Q., Yang, H.H., Wang, L., Han, B., Wang, X.R. and Lee, F. (2007) Analysis of Chloroacetanilide Herbicides in Water Samples by Solid-Phase Microextraction Coupled with Gas Chromatography-Mass Spectrometry. Analytica Chimica Acta, 591, 87-96. http://dx.doi.org/10.1016/j.aca.2007.03.044 
Scientific Research Publishing (SCIRP) is one of the largest Open Access journal publishers. It is currently publishing more than 200 open access, online, peer-reviewed journals covering a wide range of academic disciplines. SCIRP serves the worldwide academic communities and contributes to the progress and application of science with its publication.

Other selected journals from SCIRP are listed as below. Submit your manuscript to us via either submit@scirp.org or Online Submission Portal.
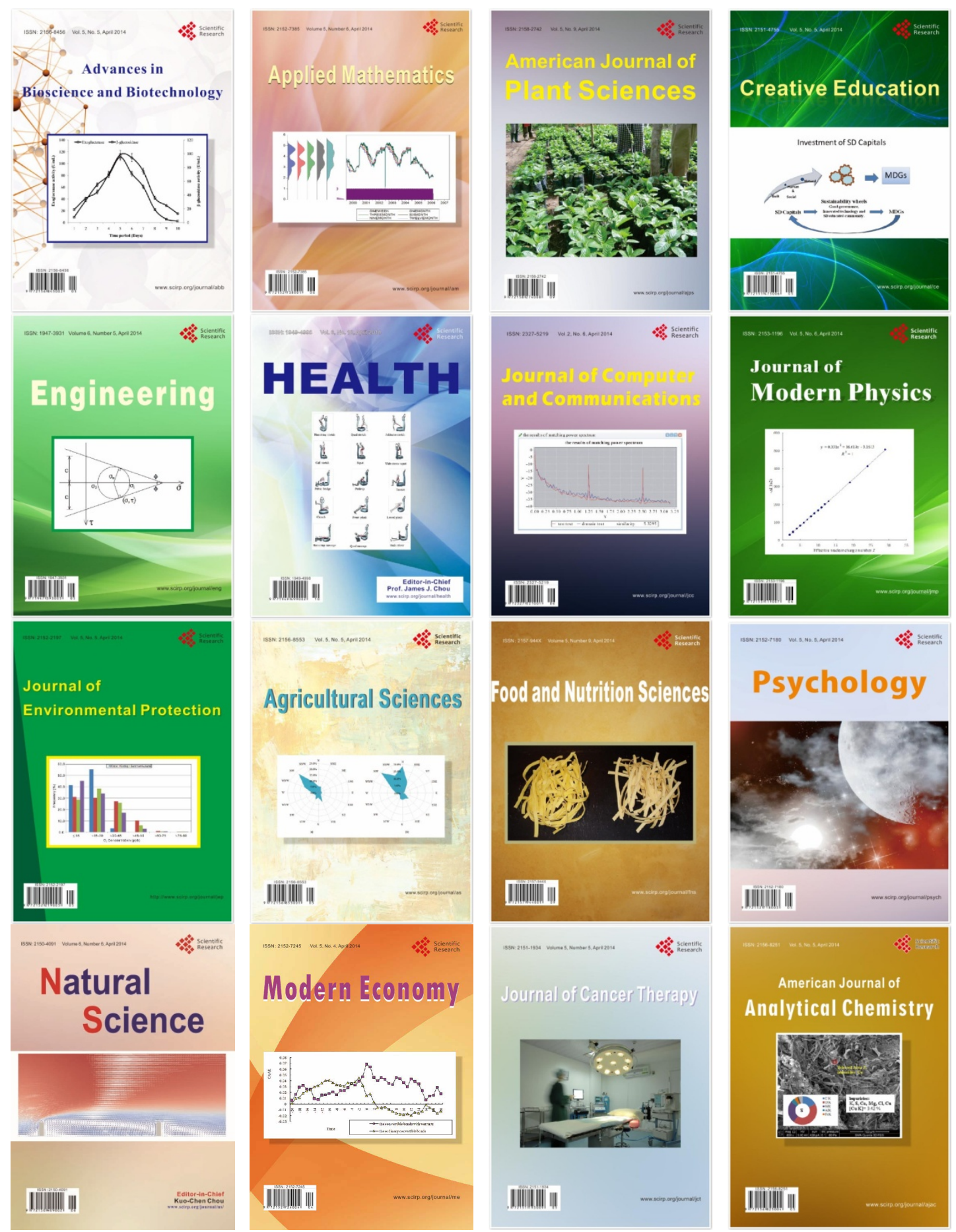